\title{
LA INDUSTRIA DEL MEDICAMENTO EN EL SENO DEL COLECTIVO QUÍMICO INDUSTRIAL: LA UNIÓN NACIONAL DE LABORATORIOS QUÍMICO-FARMACÉUTICOS (1919-1936)*
}

\author{
Raúl Rodríguez Nozal \\ Departamento de Ciencias Sanitarias y Médico-Sociales, Universidad de Alcalá
}

\begin{abstract}
RESUMEN
El asociacionismo farmacéutico industrial, al igual que ocurriera con otras actividades empresariales, experimentó un notable auge durante la Dictadura de Primo de Rivera y la II República. La Cámara Nacional de Industrias Químicas, desde Barcelona, representó a la industria química nacional hasta su asimilación definitiva por la Organización Sindical franquista, en 1939. Dentro de esta asociación, los asuntos relacionados con los productos farmacéuticos, a los que prestaremos especial atención en este trabajo, fueron gestionados por la Unión Nacional de Laboratorios QuímicoFarmacéuticos, que defendió los intereses de los productores de medicamentos industriales ante las autoridades gubernamentales, utilizando para ello recursos y mecanismos también manejados por otros grupos empresariales de presión. La inclusión de la farmacia industrial en el entramado químico nacional desligó a los fabricantes de especialidades farmacéuticas del ejercicio tradicional de esta profesión y de su entorno corporativo, circunstancia que generó encuentros, desencuentros, conflictos de intereses y, en definitiva, relaciones de amor-odio con sus colegas de oficina de farmacia y, por supuesto, con el grupo asociativo que les representaba: la Unión Farmacéutica Nacional.
\end{abstract}

PALABRAS CLAVE: Industria farmacéutica. Asociacionismo empresarial. Asociacionismo farmacéutico. España. Siglo XX.

THE PHARMACEUTICAL INDUSTRY IN THE INDUSTRIAL CHEMICAL GROUP: THE NATIONAL UNION OF CHEMICAL-PHARMACEUTICAL LABORATORIES (1919-1936)

\section{ABSTRACT}

The pharmaceutical industry associations, as it happened with other businesses, had a significant rise during the dictatorship of Primo de Rivera and II Republic. The Cámara Nacional de

\footnotetext{
* Proyecto de investigación HAR2009-09564, Ministerio de Ciencia y Tecnología.
} 
Industrias Quimicas, in Barcelona, represented the national chemical industry to its ultimate assimilation by the Organización Sindical in 1939. In this association, matters relating to pharmaceutical products - which we will specially deal with in this work - were managed by the Unión Nacional de Laboratorios Químico-Farmacéuticos, which defended the interests of pharmaceutical companies in the presence of government authorities, using the resources and mechanisms also managed by business pressure groups. The inclusion of industrial pharmacy in the Chemical lobby separated the pharmaceutical industry from traditional exercise and its corporate environment. This created ups and downs, conflicts of interests and finally, love and hate relationships with their colleagues of the pharmacy work placement and, of course, with the association that represented them: the Unión Farmacéutica Nacional.

KEY WORDS: Pharmaceutical industry. Business associations. Pharmaceutical associations. Spain. Twentieth century.

\section{I. ¿FARMACÉUTICOS O INDUSTRIALES?}

En trabajos anteriores ${ }^{1}$ hemos abordado el nacimiento del movimiento asociativo de la farmacia industrial en España, inicialmente vinculado a un sentimiento corporativo, de carácter profesional, común a toda la profesión farmacéutica. El progreso de las ciencias y de las técnicas, la irrupción del medicamento industrial, el intrusismo a menudo tolerado por el Gobierno, la inadecuada formación científica y profesional impartida desde las facultades de Farmacia o las restricciones legales a las que estaban sometidos los farmacéuticos en el ejercicio de su profesión, son algunas de las causas que alimentaron el deseo corporativo, muy presente en la historia de este colectivo profesional.

En este contexto nace la Unión Farmacéutica Nacional (UFN)22, un organismo corporativo que aglutinó y coordinó a los nuevos colegios provinciales de farmacéuticos, establecidos en España a partir de $1916^{3}$, y que representó los intereses de este grupo profesional ante las autoridades estatales - tanto durante la Dictadura de Primo de Rivera como durante la II República ${ }^{4}$,

1 Rodríguez Nozal, R. (2008), Génesis del movimiento asociativo industrial en España (1916-1931). En Rodríguez NozAl, R. y GonzÁlez Bueno, A. (coords.), El medicamento de fabricación industrial en la España contemporánea, Madrid, CERSA, pp. 69-96.

2 Sobre esta corporación, véase el trabajo de DíEz LAFuenTE, M. (1995), La Unión Farmacéutica Nacional (1913-1936). Veinticuatro años de vida corporativa, Madrid, UCM.

3 R. D. de 23 de octubre de 1916, por el que se establecen los Colegios provinciales obligatorios de la 'clase farmacéutica' (Gaceta, 26 de octubre de 1916).

4 Rodríguez NozAL, R. (2007a), Sanidad, farmacia y medicamento industrial durante la II República (1931-1936), Llull, 30, pp. 123-150. [También publicado, ese mismo año, en Papeles de la FIM, 28, pp. 163-185]; RodRíGuEZ NozAL, R. (2009), El medicamento indus- 
con gran entusiasmo, vigor, dedicación y eficacia. Valiéndonos del enfoque de Jonathan Pincus, recogido por José Luis Martínez Sanz, podemos incluir a la UFN entre los denominados «grupos de presión», es decir, aquellos que «infiltrados en cualquier instancia política, administrativa o de los medios de comunicación, presionan en beneficio de sus intereses, o repiten machaconamente hasta imponerlas como algo natural las ideas y postulados que favorecen esos intereses (...) Esos grupos hablan en nombre del Estado y del bien común, pero su motivo privado es la búsqueda de beneficios» ${ }^{5}$.

Según testimonio del que fuera secretario de esta corporación, Gustavo López García, la UFN nace con una «finalidad directa y principal (...) restaurar la ruinosa economía farmacéutica» ocasionada por el negocio del medicamento industrial y por el abandono progresivo de la tradicional fórmula magistral ${ }^{6}$, un ambicioso objetivo que pasaba, en primer lugar, por controlar y someter la disidencia industrial presente en el colectivo que representaba. Por ello, no es de extrañar que la primera iniciativa para crear un sindicato de productores de especialidades farmacéuticas en nuestro país, partiera de este potente engranaje corporativo; en 1914, la Unión Farmacéutica Nacional propone la creación de un «Sindicato Farmacéutico de la Reglamentación», del que podrían formar parte todos los farmacéuticos españoles que prepararan especialidades, siempre y cuando aceptasen las condiciones impuestas desde la UFN. El único objetivo de este sindicato o, lo que es igual, el único fin perseguido por la UFN, era la unificación y el control de precio de venta al público de las especialidades farmacéuticas y, por supuesto, el monopolio en la dispensación de este tipo de productos para las oficinas de farmacia ${ }^{7}$.

trial en España durante el Directorio Militar y la II República (1923-1936). En Moreno ToRal, E. y Ramos CARrillo, A. (eds.), Actas del 38 Congreso Internacional de Historia de la Farmacia, Córdoba, Universidad de Sevilla, s.p. [Cd-rom].

5 MARtínez SANZ, J.L. (2001), Los empresarios y sus asociaciones en la historiografía española, Cuadernos de Historia Contemporánea, 23, pp. 177-194, p. 181.

6 López García, G. (1951-1952), [Lo que fue la Unión Farmacéutica Nacional], Farmacia Nueva, 168, pp. 38-40; 169, pp. 77-81; 171, pp. 189-192; 172, pp. 231-234; 175, pp. $385-389$; 176, pp. 439-442; 177, pp. 503-506; 178, pp. 557-560; 179, pp. 600-602; 180, pp. $36-40 ; 181$, pp. $88-90 ; 182$, pp. $145-148$; 183 , pp. $207-210 ; 184$, pp. $259-266$; 185 , pp. $322-$ $323 ; 186$, pp. 365-371.

7 Sobre este asunto $c f$. Rodríguez NozAL, R. (2007b), Unidos por la fabricación. La Asociación de Productores de Especialidades Farmacéuticas (1916-1922). En GonZÁLEZ Bueno, A., Rodríguez Nozal, R. y Moreno Toral, E. (eds.), Simples y compuestos. El medicamento en la historia. Actas de las II Jornadas celebradas por la Sociedad de Docentes Universitarios de Historia de la Farmacia de España (SDUHFE). Baeza, 28/29 de abril de 2005, Madrid, SDUHFE, pp. 159-169. 
Esta iniciativa de la UFN fracasó; se trataba de un proyecto totalmente intervenido por este organismo y muy autoritario para con los productores de especialidades, quienes parecían quedar sometidos, económica y disciplinariamente, a los intereses de las oficinas de farmacia. Pese al empeño de la UFN, los farmacéuticos que preparaban medicamentos industriales escaparon de su control e iniciaron una andadura asociativa independiente a la del resto de sus colegas. La Asociación de Productores de Especialidades Farmacéuticas, creada en 1916 y de la que ya nos hemos ocupado en un trabajo anterior ${ }^{8}$, fue la primera en defender, al menos de manera contundente, a los profesionales españoles que desarrollaban su actividad en el ámbito industrial. Disuelta ésta se constituye una nueva entidad que, desde 1922 hasta 1931, representó a buena parte de los farmacéuticos productores de especialidades, la Unión General de Productores de Especialidades Farmacéuticas de España también conocida como La «Especialidad Farmacéutica»—; no fue más que una continuación de su antecesora, también radicada en Madrid y de la que formaron parte algunos de los más destacados representantes de la primera ${ }^{9}$. Desapareció en 1931, tal vez ante el empuje de otra asociación de industriales farmacéuticos radicada en Barcelona: la Unión Nacional de Laboratorios Químico-Farmacéuticos, la cual formaba parte de un organismo de mayor envergadura: la Cámara Nacional de Industrias Químicas, que representó a la industria química, la farmacéutica incluida, hasta su desaparición definitiva durante los primeros años del franquismo

La ruptura y escisión del colectivo de profesionales de la Farmacia, tradicionalmente unido hasta la popularización del medicamento industrial, quedó bien patente durante este período (1916-1931), especialmente tormentoso para las oficinas de farmacia; unos establecimientos enérgicamente representados por la UFN pero que tuvieron que soportar la hostilidad del gobierno de Primo de Rivera ${ }^{10}$, al igual que sucediera con otros grupos profesionales organizados ${ }^{11}$, y la actitud ambigua mostrada por sus colegas productores de

8 Cf. Rodríguez Nozal (2007b).

9 De esta asociación nos hemos ocupado en otro trabajo: RodRíGUEZ NOZAL, R. (2001), La defensa del industrial farmacéutico durante la Dictadura de Primo de Rivera: la «Unión General de Productores de Especialidades Farmacéuticas de España» (1922-1931) En CoBos Bueno, J.M., Pulgarín Guerrero, A. y Ausejo, E. (eds.), X Congreso de la Sociedad Española de Historia de las Ciencias y de las Técnicas. Encuentro internacional Europeo-Americano 2008, Badajoz, SEHCYT, pp. 757-766 [cd-rom].

$10 C f$. Rodríguez NozAL (2007b, 2008 y 2009).

$11 C f$. Villacorta Baños, F. (2000), Dictadura y grupos profesionales organizados, 1923-1930, Ayer, 40, pp. 51-78. 
especialidades farmacéuticas, más preocupados de extender sus redes comerciales hacia droguerías y establecimientos similares que de atender los argumentos sanitarios y corporativos defendidos desde la UFN.

La inclusión de la farmacia industrial en la Cámara Nacional de Industrias Químicas, un organismo asociativo de carácter empresarial aunque vinculado a una actividad de carácter científico, terminó por desligar a sus profesionales del entorno corporativo farmacéutico para entrar a formar parte del ámbito químico, empresarial e industrial, del cual hoy día aún forman parte. Tras la finalización de la Guerra Civil y una vez establecida la Organización Sindical Española, las empresas químicas - incluidas las farmacéuticas - constituyeron el Sindicato Vertical de Industrias Químicas, que funcionó como organismo exclusivo de representatividad empresarial y obrera, al menos, hasta los años 1960, en que empiezan a surgir, y a consentirse, iniciativas asociativas independientes del engranaje sindical franquista, entre ellas Farmaindustria que, durante los años 1970, estaría llamada a convertirse en la patronal de la industria farmacéutica en nuestro país.

\section{BAJO El AMPARO DE LA CÁMARA NACIONAL DE INDUSTRIAS QUímiCAS}

¿Por qué los patronos se han decantado a menudo por la vía asociativa, aún cuando los fundamentos del capitalismo y los modos de actuación de las patronales organizadas pueden llegar a ser bien diferentes? En opinión de Pilar Calvo Caballero, las situaciones adversas de mercado (competencia extranjera, bajadas de precios, saturación del mercado, etc.), acompañadas de actuaciones individuales infructuosas sobre aquél, han alentado el espíritu asociativo y reivindicativo de los empresarios españoles, hasta conducirles a la solicitud de medidas gubernamentales, como las de carácter proteccionista, que normalmente suelen ser contradictorias con la lógica capitalista12. Para José Luis Martínez Sanz, «la historia industrial contemporánea de España parece caracterizarse por la búsqueda de rentas o beneficios mediante el control monopolístico en casi todos los sectores ${ }^{13}$, lo que ha propiciado políticas de proteccionismo estatal, bien evidentes durante el Directorio Militar, que han contribuido a retrasar el desarrollo de la industria española respecto de la europea. Otros autores, como Philippe C. Schmitter, sitúan a los movimientos

12 Calvo Caballero, P. (1992), En torno a un debate: La lógica del comportamiento asociativo patronal. El caso de la patronal castellano-leonesa durante el primer tercio del siglo XX, Investigaciones Históricas, 12, pp. 285-300, p. 290-291.

13 Martínez SANZ (2001), p. 187. 
«corporatista» $\mathrm{y}$ «neocorporatista» en el centro del debate en torno a la reestructuración de las relaciones Estado-Sociedad; en opinión de este autor, deben interpretarse como mecanismos sin un diseño político específico, que propician «la salida no intencionada a una serie de conflictos de intereses y crisis políticas en las que ninguno de los representantes involucrados de los grupos y de las clases sociales y del Estado fue capaz de imponer sus preferencias a los demás» ${ }^{14}$.

Sea como fuere, la Cámara Nacional de Industrias Químicas hace su aparición en esta época de fortalecimiento de las asociaciones y conglomerados patronales; algunos, como el Fomento del Trabajo Nacional, ya contaban con una dilatada trayectoria en defensa de los intereses empresariales; otros, como la Confederación Gremial Española, la Confederación Patronal Española, la Federación de Industrias Nacionales o la Unión Nacional Económica — ya durante la II República - fueron creados a partir de la década de $1910^{15}$. La Cámara irrumpe con fuerza en la vida económica e industrial española durante la Dictadura de Primo de Rivera, de manera más notoria a partir de 1926 cuando es declarada de utilidad pública ${ }^{16}$; distinción reafirmada años después cuando, a propuesta del Ministro de Economía Nacional, es distinguida como institución de «carácter oficial con todos los derechos y obligaciones inherentes a las entidades de su clase» ${ }^{17}$. Sin embargo, su origen es más temprano, probablemente se remonte a $1919^{18} \mathrm{y}$, al menos, tenemos noticias de su actividad desde $1925^{19}$.

La Cámara Nacional de Industrias Químicas siguió la estela de la francesa Sociéte de Chimie Industrielle, fundada en 1917 por Paul Kesner y Jean Ge-

14 SCHMitTer, P.C. (1985), Neocorporatismo y Estado, Revista española de investigaciones sociológicas, 31, pp. 47-78, p. 51.

15 Martínez SANZ, J.L. (2002), Aproximación histórica a las organizaciones empresariales en España. I. Orígenes y evolución, Madrid, CEIM. La Unión Nacional Económica desempeñó un papel aglutinador similar al protagonizado por la Federación de Industrias Nacionales durante el Directorio Militar, como portavoz y defensa de los intereses empresariales en una época de desconfianza empresarial ante las políticas obreristas del PSOE.

16 Cf. (1926), Cámara Nacional de Industrias Químicas, Química e Industria, 3 (27), pp. 100-101; Peres Unzueta, [J.] (dir.) (1932), Anuario de Industrias Químicas, Barcelona, Cámara Nacional de Industrias Químicas, p. V.

17 Decreto de 23 de junio de 1931, firmado por el Presidente del Gobierno provisional de la República, Niceto Alcalá-Zamora Torres, y por el Ministro de la Economía Nacional, Luis Nicolau D'Olwer (Gaceta, 26 de junio de 1931).

18 «La forma actual de esta Cámara, como consecuencia de anteriores y sucesivas transformaciones de la primera entidad creada en 1919 (...)», cf. PERES UNZUETA (1932), p. V.

19 Ver las noticias aparecidas en La Vanguardia, jueves 3 de diciembre de 1925, p. 10 y miércoles 27 de enero de 1926, p. 8. 
rard y declarada de utilidad pública un año después, cuyo objetivo prioritario fue la alianza entre Ciencia e Industria gracias a la participación de las principales figuras francesas de la química e ingeniería química del momento y a la creación, en 1918, de su propio órgano de expresión, la revista Chimie et Industrie ${ }^{20}$.

Su principal objetivo fue la defensa, promoción y representación de la industria química nacional ante las autoridades políticas y científicas, tanto de España como del extranjero, en un intento por fomentar y mantener la competitividad comercial y el desarrollo científico aplicado dentro de este sector industrial. La estructura organizativa era de tipo federal, constituida a partir de las diferentes «uniones nacionales» específicas de las actividades químico-industriales representadas, entre ellas la de Laboratorios Químico-Farmacéuticos.

La propia estructura federal de la Cámara favoreció la descentralización de sus actividades hacia las distintas Uniones Nacionales quienes, en la práctica, asumieron el control corporativo de la actividad química que representaban. No obstante, la propia Cámara aceptó el peso representativo, reivindicativo e, incluso, organizativo de algunos asuntos de interés común para todas las industrias químicas, como los relativos a propiedad industrial, fiscalidad, control de calidad, reivindicación laboral y organización de eventos científicos.

\section{LA UNIÓN NACIONAL DE LABORATORIOS QUÍMICO-FARMACÉUTICOS}

En un principio denominada «Agrupación de Laboratorios farmacéuticos de la Cámara Nacional de Industrias Químicas» ${ }^{21}$, esta asociación disponía de su propio Consejo Directivo, formado por unos 15-20 miembros, todos ellos destacadas personalidades de la industria farmacéutica española de aquel período; celebraba sus juntas generales en los locales de la Cámara Nacional de Industrias Químicas 22 .

20 LóPez Franco, A. (1929), Noveno Congreso de Química Industrial, Revista de Obras Públicas, 2536, pp. 416-417. En España, la publicación homóloga a ésta se llamó igual: Química e Industria.

21 Con anterioridad a 1926 estas «Uniones» se llamaban «Agrupaciones», véase, por ejemplo: (1925), De Especialidades farmacéuticas, Química e Industria, 2 (15), p. 106.

22 Conocemos las siguientes: martes 23 de abril de 1929, a las seis de la tarde en la calle Vía Layetana 56 (véase la noticia aparecida en La Vanguardia, 19 de abril de 1929, p. 7); jueves 5 de junio de 1930, a las seis de la tarde en la calle Vía Layetana 56 primero ( $c f$. la noticia de La Vanguardia, 5 de junio de 1930, p. 12); miércoles 18 de julio de 1934, a las cuatro de la tarde en la calle Diputación 306 principal ( $c f$. la noticia de La Vanguardia, 18 de 
Al menos desde 1931, durante la II República, llegó a actuar como patronal en Barcelona, negociando con el poder sindical las condiciones laborales y los salarios de los trabajadores de este sector ${ }^{23}$. Durante estos años de marcado nacionalismo también tuvo que hacer frente a los intentos del colectivo médico para boicotear la prescripción de especialidades farmacéuticas preparadas en Cataluña e, incluso, los medicamentos extranjeros con representación catalana; el desafío de la profesión médica no hizo más que acrecentar la unidad de los laboratorios catalanes, para quienes esta maniobra tan sólo pretendía perturbar el gobierno de la recién instaurada República y mancillaba su honorabilidad, ya que nunca habían tenido un sentimiento de desafección hacia España y menos en aquellas circunstancias históricas, en principio más proclives a la catalanidad ${ }^{24}$.

El alma mater de esta asociación de industriales farmacéuticos fue el catalán Santiago Pagés Maruny (1888-1972), presidente de ella durante toda su existencia y uno de los más valiosos puntales con los que contó la Cámara Nacional de Industrias Químicas, lo que sin duda influyó notablemente en la importante actividad desarrollada por la Unión Nacional de Laboratorios Químico-Farmacéuticos, una de las más activas y con mayor protagonismo de entre las que componían la Cámara. Entre otros cargos, nombramientos y distinciones $^{25}$ fue asesor de la Conselleria de Sanitat i Asistencia Social para lo relativo a laboratorios químico-farmacéuticos, desde el 25-I-1936, por nombramiento del Conseller de Sanitat i Asistencia Social, Felipe Betrán y Güell; y, finalizada la Guerra Civil fue nombrado Presidente de la Cámara Nacional de Industrias Químicas hasta que esta asociación fue asimilada por la Organización Sindical franquista. Ocupó la presidencia del recién creado

julio de 1934, p. 6); viernes 8 de mayo de 1936, a las cuatro de la tarde en la calle Diputación 306 principal (véase la noticia aparecida en La Vanguardia, 8 de mayo de 1936, p. 8).

23 «Esta asociación, junto con el Sindicato de Productos Químicos — afecto a la CNT—, han terminado las negociaciones para unas bases de trabajo para los laboratorios de Barcelona y su radio, cuya firma tuvo efecto el sábado último», la nueva tabla salarial entraría en vigor a partir del 21 de septiembre de 1931, cf. La Vanguardia, martes 6 de octubre de 1931.

24 Carta de los Laboratorios Químico-Farmacéuticos de Cataluña a la Unión Nacional de Laboratorios Químico-Farmacéuticos, 22 de mayo de 1931. Publicada en 1931 por El Monitor de la Farmacia y de la Terapéutica, 1148, pp. 340-341, por La Voz de la Farmacia, 18, pp. 364-365 y por El Restaurador Farmacéutico, 86 (12), pp. 315-317. Esta última publicación, además de la carta, reprodujo una lista con los 58 firmantes. La Voz de la Farmacia, además, incluyó un artículo editorial propio.

25 Sobre este personaje $c f$. JoRdi GonzÁlez, R. (1972), Dr. Santiago Pagés Maruny, Boletín Informativo de Circular Farmacéutica, 37, pp. 3-9. 
Sindicato Nacional de Industrias Químicas — probablemente fue su primer presidente - hasta julio de $1941^{26}$.

3.1. En defensa de su producto comercial: labor reivindicativa y acuerdos comercializadores sobre especialidades farmacéuticas

De acuerdo con José Luis Martínez Sanz, las asociaciones empresariales proporcionan «cohesión de clase, refuerzo de autoridad, bienes políticos, servicios y amparo ${ }^{27}$. Los mecanismos, instrumentos o estrategias que utilizan, perfectamente reconocibles en la patronal química y, por supuesto, en su división farmacéutica, son múltiples: búsqueda de apoyos en los poderes e instituciones locales, realización de campañas organizadas de prensa, presión sobre los representantes a Cortes - especialmente entre aquellos miembros electos de su lobby - cartas, telegramas, mensajes y visitas al Gobierno y sus Ministros, manifestaciones y concentraciones, etc ${ }^{28}$.

La Unión Nacional de Laboratorios Químico-Farmacéuticos, con un entusiasta e incombustible Santiago Pagés Maruny al frente, trató de representar los intereses concretos de los fabricantes españoles de especialidades farmacéuticas, aquéllos no contemplados directamente por las líneas de actuación corporativas emprendidas por la propia Cámara Nacional de Industrias Químicas, tanto ante sus colegas de oficina de farmacia - representados por la Unión Farmacéutica Nacional- como ante las autoridades gubernamentales del Directorio Militar y, posteriormente, de la II República. Durante algunos años - aproximadamente, entre 1925 y 1931 - compartió la defensa de los industriales farmacéuticos con otra asociación radicada en Madrid, la Unión General de Productores de Especialidades Farmacéuticas de España, que pro-

26 Según información proporcionada por Ramón Jordi González, Santiago Pagés Maruny carecía de antecedentes políticos anteriores a la Guerra Civil —expediente de depuración 809. Año 1941- y llegó a afiliarse a FET de las JONS. «Fue perseguido por sus ideas, lo que no impidió que proporcionara medicamentos a la decana de excautivos, Pilar Millán Astray. Remitió también a la zona nacionalista documentación perteneciente a la Unión de Laboratorios, que le había sido solicitada», cf. JORDI GONZÁLEZ, R. (2000), Colectanea de "speciers", mancebos boticarios, boticarios farmacéuticos practicantes de farmacia y farmacéuticos en Cataluña (1207-1997), Girona, Fundació Uriach 1838. Sobre el Laboratorio Químico Biológico Doctor S. Pagés Maruny, véase la documentación conservada en el Archivo General de la Administración, sección Sindicatos, legajo (06) 34/14311.

27 MARTínez SANZ (2001), p. 187.

28 Cf. MARTíNEZ SANZ (2002). 
bablemente desapareció por no poder compatibilizar sus intereses económicos con la «conciencia corporativa» de pertenencia a un determinado grupo profesional; la Unión General era aún una asociación de marcado carácter farmacéutico, con integrantes - principalmente laboratorios anejos o, incluso, algunos independientes ${ }^{29}$ — que también participaban de los intereses defendidos por la UFN. Por el contrario, y aún existiendo vinculaciones con el ámbito de la oficina de farmacia, La Unión Nacional de Laboratorios Químico-Farmacéuticos ya no era un grupo corporativo farmacéutico sino un núcleo de poder industrial, firmemente respaldado por un potente engranaje empresarial como era la catalana Cámara Nacional de Industrias Químicas.

Durante el período 1925-1931 las dos asociaciones de industriales farmacéuticos fraguaron una serie de acuerdos con la UFN, en materia de precios para las especialidades farmacéuticas, que acabarían obteniendo refrendo legal en 1928 con la redacción de la Real Orden de 21 de abril de 1928, que establecía la prohibición de la venta de especialidades farmacéuticas a precios distintos de los fijados en los envases o al reparto de bonificaciones, de cualquier naturaleza, que pudieran burlar lo así dispuesto ${ }^{30}$. Esta disposición legal, calificada de «dignificadora» por la profesión farmacéutica ${ }^{31}$, fue en realidad promovida y solicitada por todos los colectivos implicados en la fabricación y venta de especialidades farmacéuticas, obviamente por las oficinas de farmacia e industriales farmacéuticos, pero también por drogueros e incluso comerciantes de comestibles, cuya presencia en este negocio constituía un verdadero quebradero de cabeza para la UFN.

Esta corporación farmacéutica trató, por todos los medios, de expulsar a estos comerciantes (drogueros, tenderos, etc.) del mercado de las especialidades farmacéuticas, pero la respuesta que, al menos durante unos años, encontró en la orilla industrial no fue ni la deseada ni, probablemente, la esperada. La Unión General de Productores de Especialidades Farmacéuticas se mostró evasiva y críptica ante la petición de monopolio en la dispensación de estos productos por parte de las oficinas de farmacia; por su parte, la Unión Nacional de Laboratorios Químico-Farmacéuticos fue más explícita en sus postula-

29 Sobre la tipificación legal de los laboratorios farmacéuticos en España, véase GoNZÁLEz Bueno, A. y RodríGuez NozAL, R. (2005), Fiscalidad e industrialización: las oficinas de farmacia en Madrid (1907-1925), Schironia, 4, pp. 39-43.

30 Gaceta, 24 de abril de 1928.

31 GavaldÁ, R. (1928), Una disposición legal dignificadora. El precio de venta de las especialidades, El Restaurador Farmacéutico, 83 (8), pp. 201-204. 
dos, defendidos sin ambigüedades por Santiago Pagés Maruny ${ }^{32}$ ante la indignación de sus compañeros de profesión ${ }^{33}$. Unos años antes, el farmacéutico J. Viladot Puig ya había acusado a Santiago Pagés Maruny de no manifestarse claramente a favor de la dispensación exclusiva de las especialidades farmacéuticas en las oficinas de farmacia ${ }^{34}$. El presidente de la Unión Nacional de Laboratorios Químico-Farmacéuticos no pudo anteponer su «conciencia de clase» al interés comercial y a la posible pérdida de un mercado, probablemente más abundante y ventajoso que el que le podrían ofrecer sus compañeros de profesión ${ }^{35}$.

Fueron años difíciles, de continuos enfrentamientos entre los farmacéuticos más tradicionales, asentados en sus oficinas de farmacia, y aquéllos más centrados en la producción industrial de medicamentos. En 1928, la Unión Nacional de Laboratorios Químico-Farmacéuticos redactaba un documento - que pensaban someter a la consideración y firma de sus socios europeos, es decir, la Associazione Italiana della Specialita Farmaceutiche y la Chambre Syndicale de Produits Pharmaceutiques de París-, en respuesta a un «raport de los señores Dr. J.J. Hofman y Dr. A. Schamelhout sobre el ejercicio de la Farmacia y remedios para solventar su situación», publicado en el número 2 del Boletín de la Federación Internacional Farmacéutica. En opinión de la Unión, «en cuatro puntos convergen todas las apreciaciones publicadas al efecto en el Boletín de la Federation Internationales [sic] Pharmaceutique, la primera de ellas, que la especialidad farmacéutica es la causa de la ruina del farmacéutico detallista; la segunda, que la mayoría de las especialidades no

32 Carta de Santiago Pagés Maruny, presidente de la Unión Nacional de Laboratorios Químico-Farmacéuticos, Barcelona, 23 de agosto de 1930, publicada por La Voz de la Farmacia, 8, pp. 390-391.

33 «Días pasados se reunió en Junta general la 'Unión Nacional de Laboratorios Químico-farmacéuticos' (...) para decidir sobre su conducta en relación con la petición de la 'Unión Farmacéutica Nacional' de derogación del artículo 13 del Reglamento de especialidades. Fué la sesión borrascosa, y terminó con el acuerdo, adoptado por mayoría, de pedir el mantenimiento de la facultad concedida a los drogueros de vender especialidades farmacéuticas. A los pocos días, se reunió también la Directiva de 'La Especialidad Farmacéutica', y, no sabemos si también por mayoría o por unanimidad, acordó manifestarse en igual sentido, lo que hizo visitando al Ministro. Los que componen la una y la otra asociación son farmacéuticos, aunque no lo parezca», cf. (1930), Los Especialistas, La Farmacia Española, 62 (14), p. 272.

34 Viladot Puig, J. (1926), Sobre especialidades. Comentando al Dr. Pages Maruny, El Restaurador Farmacéutico, 81 (3), pp. 60-64.

35 PAgÉS MARUNY, S. (1926a), Aclaraciones solicitadas a mi artículo sobre Valor social y profesional de las especialidades farmacéuticas, El Restaurador Farmacéutico, 81 (4), pp. 90-92. 
cumplen ni pueden cumplir fin terapéutico alguno; la tercera, que estimula al público a la medicación directa con exclusión de toda intervención médica, y la cuarta que el farmacéutico expende en sus oficinas medicamentos que no puede controlar» ${ }^{36}$.

El documento-contestación redactado por la Unión Nacional de Laboratorios Químico-Farmacéuticos en respuesta a las opiniones de la Federación Internacional Farmacéutica es francamente interesante; los fabricantes españoles defienden la eficacia terapéutica de sus productos, su control médico y la certificación de producto proporcionada por ellos mismos. Respecto del primero de los asuntos, piensan que no parece justificable el plantear un supuesto perjuicio de las especialidades farmacéuticas utilizando argumentos de tipo económico para el colectivo de oficinas de farmacia; lo cierto es que los productores son muy duros en este asunto $\mathrm{y}$, tal vez, poco considerados e irónicos para con sus compañeros, a quienes sugieren que se dediquen a otros menesteres, habida cuenta que suficiente tienen con responsabilizarse de la pureza de los productos oficinales y magistrales que preparan.

Ante este caldeado ambiente, la Unión Farmacéutica Nacional, por su parte, mantuvo la calma y modificó su estrategia, esta vez utilizando paciencia y negociación; ofrecieron a los laboratorios farmacéuticos la supresión de la obligatoriedad de indicar la fórmula en la etiqueta del medicamento, así como la exención de responsabilidades hacia los laboratorios respecto de aquellas especialidades vendidas a colectivos o particulares no autorizados ${ }^{37}$.

El pacto no se hizo esperar, durante 1930 productores y detallistas ya se habían puesto de acuerdo para dejar fuera del negocio a drogueros y a otros comerciantes; en principio la alianza fue sellada por la UFN y la Unión Nacional de Laboratorios Químico-Farmacéuticos, y posteriormente acatada por la Unión General de Productores de Especialidades Farmacéuticas, en fechas ya muy cercanas a su desaparición como asociación industrial, y también por los representantes de los Colegios de Médicos de Madrid y de Farmacéuticos de Barcelona. La propuesta conjunta, a presentar ante las autoridades estatales, pasaba por una nueva redacción del Reglamento para la Elaboración y Venta de Especialidades Farmacéuticas en lo relativo a su controvertido artículo 13, en el sentido de subrayar la obligatoriedad de dispensar cualquier tipo de especialidad farmacéutica, sin excepciones, únicamente en oficinas de

36 (1928), Federation Internationale Pharmaceutique, Química e Industria, 5 (59), pp. 300-301.

37 (1929), Unión de laboratorios químico-farmacéuticos, El Monitor de la Farmacia y de la Terapéutica, 1106, p. 446. 
farmacia; a comienzos de 1931 el artículo 13 quedaba derogado, no sin gran indignación por parte de los negocios de droguería, que llegaron a presentar un recurso, aunque sin éxito, ante el Tribunal Supremo por esta decisión gubernamental. La UFN, con la aquiescencia de la industria, había logrado un monopolio sobre la venta de medicamentos, ya fueran magistrales o industriales, que aún hoy día se mantiene ${ }^{38}$.

\subsection{Regulación administrativa y control sanitario de los medicamentos}

En diciembre de 1925 se crea el Instituto Técnico de Comprobación, un organismo estatal que habría de controlar la calidad y pureza de las especialidades farmacéuticas, mediante comprobaciones analíticas de las fórmulas declaradas por sus propietarios, una garantía sanitaria no contemplada hasta entonces en España para este tipo de productos, ni siquiera en el Registro para la Elaboración y Venta de Especialidades Farmacéuticas publicado un año antes ${ }^{39}$. La entonces Agrupación de Laboratorios Farmacéuticos de la Cámara Nacional de Industrias Químicas aceptó de buen grado esta iniciativa gubernamental, aunque propuso la utilización de una serie de laboratorios con el fin de llevar a cabo los contraanálisis en aquellos casos de disconformidad con la analítica realizada ${ }^{40}$.

38 Sobre este asunto, véanse algunos trabajos anteriores: RoDRíGUEZ NOZAL, R. (1999), De la fórmula magistral a la especialidad farmacéutica: el cambio de actitud frente a las nuevas prácticas operatorias. En Puerto SARMiento, F.J. et al. (coords.), 1898. Sanidad y Ciencia en España y Latinoamérica durante el cambio de siglo, Madrid, Doce Calles, pp. 239-257; RODRÍGUEZ NOZAL (2008). Este ambiente favorable, entre quienes fabricaban las especialidades farmacéuticas y quienes las dispensaban, se mantuvo durante los años de la II República. En 1933 se firmó un pacto entre la UFN y la Unión Nacional de Laboratorios QuímicoFarmacéuticos, para gestionar la devolución de este tipo de preparados, que fue generosamente reseñado por la prensa farmacéutica de la época, cf. El Monitor de la Farmacia y de la Terapéutica, 1200, pp. 410-411; (1933), La Voz de la Farmacia, 42, pp. 377-379; (1933), Farmacia Nueva, 3, pp. 55-56. El pacto fue firmado, de un lado, por el secretario (J.H. Prieto) y presidente (Dr. Fr. Saval) de la Unión Farmacéutica Nacional y, del otro, por el secretario general (Fernando Bonafont de Cortada) y el presidente (Dr. Pagés Maruny) de la Unión Nacional de Laboratorios Químico Farmacéuticos.

39 Sobre este asunto $c f$. RodríGueZ NozAL, R. y GonZÁlez BuENO, A. (2005), Entre el arte y la técnica. Los orígenes de la fabricación industrial del medicamento, Madrid, CSIC; RoDRÍGUEZ NOZAL, R. y GONZÁlez BuENO, A. (2004), De objeto de consumo a producto sanitario: primeros proyectos sobre el control sanitario del medicamento en España, Llull, 27, pp. 147-164.

40 Carta de Santiago Pages Maruny, presidente de la Agrupación de Laboratorios Farmacéuticos de la Cámara Nacional de Industrias Químicas, al Ministro de la Gobernación. Barce- 
También solicitaban una disminución en la tributación exigida a los laboratorios farmacéuticos y, en reuniones posteriores de esta Agrupación, formularon otras objeciones en un afán, más que por ralentizar o dificultar esta medida gubernamental, por contribuir a una mejora de la reglamentación sobre el control sanitario de los medicamentos ${ }^{41}$. Según lo manifestado por esta Agrupación, una hipotética Real Orden de 20 de agosto de $1926^{42}$ «resolvería, en lo fundamental, las principales demandas que dicha Unión, apoyada por la Cámara, elevó en momento oportuno al Excmo. Señor Ministro de la Gobernación» ${ }^{43}$.

En este mismo ámbito de la regulación administrativa y control sanitario de las especialidades farmacéuticas, también debemos señalar otras actuaciones de la Unión Nacional de Laboratorios Químico-Farmacéuticos, con menor repercusión o éxito ante las autoridades gubernamentales. Es el caso de su deseo por modificar la legislación sobre publicidad de productos farmacéuti$\cos$, a fin de controlar la literatura que acompañaba a estos productos, así como sus reclamos publicitarios, con el propósito de no extralimitar las indicaciones terapéuticas, es decir, por motivos de salud ${ }^{44}$; o su extrañeza ante la obligatoriedad de tener que registrar de nuevo una especialidad farmacéutica debido, únicamente, a cambios en la razón social de los laboratorios ${ }^{45}$.

No tuvieron más éxito las protestas formales llevadas a cabo tras la publicación de la Orden Ministerial de 3 de diciembre de 193146, firmada por el que fuera Director general de Sanidad durante la II República, Marcelino Pascua, según la cual no podrían comercializarse aquellos productos biológi-

lona, 31 de diciembre de 1926 [la carta también va firmada por Fernando Bonafont de Cortada, secretario general de la Cámara], publicada en 1926, El Restaurador Farmacéutico, 81 (2), pp. 42-44 y Química e Industria, 3 (24), pp. 20-21, de donde tomamos los datos.

41 (1926) Observaciones que han sugerido a la industria farmacéutica española incorporada, los Reales decretos anteriores relativos al Instituto Técnico de Comprobación, Química e Industria, 3 (29), pp. 162-163.

42 No hemos podido identificar esta disposición como publicada por el diario oficial $\mathrm{La}$ Gaceta; es probable que, finalmente, se tratara de una norma de rango menor.

43 (1926), Movimiento Corporativo, Química e Industria, 3 (32), p. 255.

44 PAGÉS MARUnY, S. (1926b), Valor social y profesional de las especialidades farmacéuticas, El Restaurador Farmacéutico, 81 (2), pp. 39-41.

45 Una medida que califican de incómoda y perjudicial, por lo que solicitan «una aclaración categórica de la Jefatura de Servicios Farmacéuticos», a quien se dirigen de manera oficial, cf. (1929), Unión Nacional de Laboratorios Químico-Farmacéuticos, Química e Industria, 6 (60), pp. 14-15.

46 Gaceta, 4 de diciembre de 1931. La lista de sustancias sometidas a control es corregida en la Orden de 5 de diciembre de 1931 (Gaceta, 9 de diciembre de 1931). 
cos - los mencionados en esa disposición, como sueros, vacunas, filtrados bacterianos, fermentos lácticos, bacteriófagos, tuberculinas, etc.- procedentes de lotes nuevos, importados o fabricados en España, sin el análisis previo y el visto bueno del Instituto Técnico de Farmacobiología ${ }^{47}$. En opinión de Santiago Pagés Maruny esta medida no haría otra cosa que dificultar a los fabricantes de nuevos productos biológicos y retrasar su puesta en el mercado; a pesar de todo, recomendaba a los laboratorios que entregaran lo antes posible sus muestras a este Instituto, pero también solicitaba del Director general de Sanidad más tiempo para adaptarse a esta nueva situación y que los controles analíticos fueran sólo voluntarios, así como otra serie de peticiones a considerar por ese organismo administrativo ${ }^{48}$.

Donde sí debió pesar la opinión de los productores de especialidades farmacéuticas fue en la regulación de estupefacientes y medicamentos sometidos a vigilancia singular. Estos productos contaban, desde 1918, con un «Reglamento para el comercio y dispensación de las substancias tóxicas, y en especial de las que ejercen acción narcótica, antitérmica o anestésica», donde se daban las instrucciones pertinentes para la introducción, circulación y comercialización de sustancias como los opiáceos, la cocaína y sus derivados, así como «los alcaloides, glucósidos y principios conocidos como narcóticos, anestésicos, antitérmicos, antigenésicos y abortivos», para cuya venta en las oficinas de farmacia era «requisito indispensable la prescripción facultativa, escrita y firmada por el Médico, quedando la fórmula en poder del farmacéutico, y necesitando ser renovadas si, a juicio del Facultativo, la prescripción necesitase ser repetida una ó más veces» ${ }^{49}$. No se trataba de una norma en exceso restrictiva, como tampoco lo era el Reglamento para la Elaboración y Venta de Especialidades Farmacéuticas de 1924, en lo relativo a estos productos, ni tampoco la legislación generada durante los años siguientes, donde se fijaban unas pautas de control, y punitivas, de carácter muy general ${ }^{50}$.

47 Un Decreto de 20 de enero de 1931 (Gaceta, 21 de enero de 1931) disolvía el Instituto Técnico de Comprobación y creaba el Instituto Técnico de Farmacobiología, dependiente de la Dirección General de Sanidad y heredero del anterior.

48 Instancia de la Unión Nacional de Laboratorios Químico Farmacéuticos, firmada por su presidente, Santiago Pagés Maruny y presentada ante el Director general de Sanidad. Madrid, 19 de diciembre de 1931; reproducida en 1932, El Restaurador Farmacéutico, 87 (2), pp. 5-7. Véanse también las Circulares de 31 de abril de 1932 (Gaceta, 2 de abril de 1932) y 31 de enero de 1935 (Gaceta, 1 de febrero 1935).

49 Reglamento de 31 de julio de 1918 (Gaceta, 6 de agosto de 1918).

$50 \quad$ R. O. de 17 de enero de 1927 (Gaceta, 18 de enero de 1927) y Circular de 19 de enero de 1927 (Gaceta, 22 de enero de 1927). 
En 1927, tal vez motivado por una mala experiencia personal con estas sustancias $^{51}$, Santiago Pagés Maruny escribió al Ministerio de la Gobernación dando su opinión sobre la mejor manera de legislar sobre tóxicos y de ejecutar sus actuaciones de control, con el objeto de tratar de reprimir el tráfico clandestino de sustancias estupefacientes. Su opinión quedó resumida en una serie de comentarios y propuestas concretas, donde se subraya la importancia de disponer de talonarios numerados y especiales para tóxicos facilitados por las autoridades sanitarias; la necesidad de emplear en toda España recetas exclusivas para tóxicos; el establecimiento de servicios de policía que vigilaran estos asuntos relacionados con tóxicos y estupefacientes, la importancia del «registro foliado para tóxicos que voluntariamente llevan los Laboratorios que no importan directamente las substancias estupefacientes»; asimismo, se hace ver el contrasentido que representaba la dispensación al público de estupefacientes en forma de especialidades y «el hecho de no permitir al farmacéutico la administración al público de dosis terapéuticas de laudano»; $\mathrm{y}$, por último, propone que los dentistas pudieran, «mediante recetas facilitadas por el Colegio de Médicos proporcionarse especialidades farmacéuticas, tales como anestésicos, cáusticos, etc., etc., de imprescindible uso para el ejercicio de su profesión ${ }^{52}$.

Tres días después de presentar este escrito ante las autoridades correspondientes, el Gobernador Civil de Barcelona, Joaquín Miláns del Bosch, emitía una Circular en la que obligaba a la utilización de recetas de estupefacientes para la dispensación de este tipo de sustancias ${ }^{53}$. Un año más tarde, en la primavera de 1928, la restricción en la distribución y venta de estupefacientes ya no era un asunto restringido a Madrid o Barcelona; el Real Decreto-Ley del Ministerio de la Gobernación, de 30 de abril de $1928^{54}$, afrontaba con deci-

51 Santiago Pagés Maruny sufrió un proceso judicial por supuesto atentado contra la salud pública; el fiscal acabó retirando la acusación, al entender que fue un compañero el que falsificó su firma en diferentes albaranes «que a su nombre se le solicitaban inyectables de morfina por valor total de 60 pesetas», $c f$. (1927), Unión de laboratorios farmacéuticos de España, Química e Industria, 4 (36), p. 24.

52 [PAgÉs MARUnY, S.] (1927), Algunas deficiencias en la actual legislación de tóxicos. Observaciones del doctor Pagés Maruny, Presidente de la Unión de Laboratorios Químicofarmacéuticos de España, de la Cámara Nacional de Industrias Químicas, sometidas a la consideración de los Excmos. Señores Director General de Sanidad, Fiscal del Tribunal Supremo Gobernador Civil de Barcelona, Química e Industria, 4 (37), pp. 50-51.

53 (1927), Circular del Gobernador Civil de Barcelona, de 4 de febrero de 1927, Química e Industria, 4 (38), p. 77.

54 Gaceta, 5 de mayo de 1928, parcialmente modificado por el R. D.-Ley de 13 de noviembre de 1928 (Gaceta, 15 de noviembre de 1928). 
sión una regulación que, probablemente, fue espoleada por los convenios internacionales existentes sobre esta materia y dinamizada gracias a la presión ejercida por la Unión Nacional de Laboratorios Químico-Farmacéuticos, con S. Pagés Maruny al frente ${ }^{55}$. Esta nueva disposición fue pionera en su ámbito y abrió paso a un fértil período legislador, sobre todo durante la II Repúbli$\mathrm{ca}^{56}$, relativo a sustancias tóxicas, restricción de estupefacientes y control de toxicomanías. Las recetas oficiales y los libros de estupefacientes entrarán a formar parte, ya de manera generalizada, en la vida cotidiana de las oficinas de farmacia.

\subsection{Exportación de medicamentos}

En alguna otra ocasión ${ }^{57}$ hemos manifestado que el medicamento industrial en España fue un producto inicialmente ajeno a la Farmacia, más propio de drogueros e industriales que de boticarios y, en su mayoría, procedente de la importación, al menos durante el siglo XIX. Las especialidades farmacéuticas fueron lentamente asumidas por los profesionales del medicamento, no sin dificultades y controversias importantes en el seno de este colectivo, hasta conseguir - de manera definitiva en 1936 - el monopolio en la dispensación de estos productos. Los reglamentos para la elaboración y venta de especialidades farmacéuticas, de 1919 y 1924, vinieron a poner orden en un mercado en auge y próspero para los fabricantes españoles, que comenzaban a no conformarse con vender sus productos, de manera exclusiva, en territorio nacional. España estaba pasando de importadora a exportadora de especialidades farmacéuticas, sobre todo hacia zonas como Portugal o América Latina.

En octubre de 1928, el Consejo Directivo de la Unión Nacional de Laboratorios Químico-Farmacéuticos acordó remitir una instancia al presidente del Consejo de Ministros, en la cual se exponían «las dificultades con que tropieza la exportación de nuestras especialidades farmacéuticas a causa de los sis-

55 No fue la última vez que se dirigió a las autoridades por un asunto relacionado con los estupefacientes. En mayo de 1929 lo hizo, en nombre de la Unión Nacional de Laboratorios Químico-Farmacéuticos, ante el Colegio Oficial de Farmacéuticos de Barcelona y el Ministro de la Gobernación, expresando su preocupación por el perjuicio que podría tener para los laboratorios nacionales la pretensión de Juan Planellas Ripio de conseguir el monopolio en la fabricación, importación y venta de tóxicos, $c f$. JORDI GONZÁLEZ, R. (1982), Cien años de vida farmacéutica barcelonesa (1830-1939), Barcelona, R. Jordi González, p. 231.

56 RODRÍGUEZ NOZAL (2007a).

57 RodríGUEz NozAL (1999). 
temas ultra-proteccionistas empleados por algunos países ${ }^{58}$. En opinión de este colectivo, el caso de Portugal podría ser especialmente dañino para sus intereses, sobre todo si finalmente se publicaba su reglamento de especialidades farmacéuticas. Esta situación motivó la redacción y envío de dos cartas, cuyas reclamaciones fueron estudiadas por las autoridades portuguesas aunque, probablemente, éstas no tuvieron mayor alcance o consideración gubernamental ${ }^{59}$.

En la primera de estas cartas manifestaban que el nuevo reglamento portugués «impediría definitivamente y de la manera más absoluta la exportación a dicho país de nuestras especialidades farmacéuticas», protesta que, al parecer, también habían cursado otros países como Francia, Italia o Alemania, con quienes ya se estaba colaborando en estos asuntos ${ }^{60}$. Entre otros productos, la norma portuguesa impedía la introducción de especialidades extranjeras que tuvieran «un similar nacional» y obligaba a que los permisos para las empresas extranjeras tuvieran que ser renovados cada seis años, tiempo suficiente para que un fabricante portugués copiase cualquier medicamento importado ${ }^{61}$. La segunda misiva abundaba en la denuncia del planteamiento ultraproteccionista establecido por algunos Gobiernos como el portugués que, valiéndose de aranceles abusivos y restricciones legislativas de tipo sanitario, vulneraban la deseable mutua reciprocidad aduanera y comercial que debería existir entre países involucrados en estas actividades ${ }^{62}$.

Sin embargo, y en un alarde de prestidigitación dialéctica, todos los argumentos esgrimidos contra el proteccionismo portugués se transformaban en papel mojado cuando lo que se trataba de defender eran los intereses de los productores de sueros y vacunas españoles ante sus homólogos europeos. Argumentaban que los productores españoles eran capaces de fabricar cantidades superiores a las que se necesitaban para abastecer el mercado nacional y que la competencia extranjera era muy perjudicial para los intereses nacionales, al tratarse de casas más antiguas que las españolas, con gran capacidad

58 (1928), Consejo Directivo. 5 de octubre de 1928, Química e Industria, 5 (58), pp. 269-270.

$59 \quad C f$. (1929), Nuestras especialidades en Portugal, Química e Industria, 6 (61), p. 43.

60 Cf. (1928), Algunas noticias de interés sobre especialidades farmacéuticas, Química e Industria, 5 (58), pp. 270-271.

61 (1928), Protesta contra el Proyecto del gobierno de Portugal, relativo a Reglamentos y Venta de Especialidades Farmacéuticas, Química e Industria, 5 (58), p. 270.

62 (1928), Observaciones de la Unión Nacional de Laboratorios Químico-Farmacéuticos a la Presidencia del Consejo de Ministros y a la Vicepresidencia del Consejo de la Economía Nacional, acerca de las condiciones en que se efectúa la exportación de nuestras especialidades farmacéuticas, Química e Industria, 5 (58), p. 270. 
productiva lo que les permitía mantener precios muy competitivos; por si fuera poco, se veían favorecidas por un arancel poco gravoso. En definitiva, la Unión de Laboratorios Químico-Farmacéuticos solicitará del gobierno una protección de 13 pts. por cada kilo de sueros y/o vacunas, aproximadamente un $10 \%$ del precio de coste ${ }^{63}$.

No sería ésta la última vez que los fabricantes españoles de medicamentos se manifestaran en relación a estos asuntos de índole arancelaria, haciendo gala de una ambigüedad argumental medida, siempre en beneficio de sus propios intereses; es el caso de la petición formulada ante el Ministro de Economía, en diciembre de 1928, solicitando un trato de mutua reciprocidad comercial con potencias como Italia o Francia y, de manera simultánea, una relación de hegemonía colonialista paterno-filial para con los países de la América Latina ${ }^{64}$.

El Ministro de Economía contestó a la Unión Nacional de Laboratorios Químico-Farmacéuticos recordándole que los tratados firmados entre España y otros países contemplaban la mutua reciprocidad «del trato de nación más favorecida», por lo que «los productos químico-farmacéuticos de fabricación española deben obtener en sus respectivos mercados el referido trato y disfrutar, por tanto, de las ventajas de que gocen los de otras procedencias» ${ }^{65}$.

\subsection{Otras actuaciones}

La Unión Nacional de Laboratorios Químico-Farmacéuticos también trataría de reclamar, para sus asociados, aquellos productos que se situaban en la frontera entre lo medicinal y la higiene cosmética. Es el caso de los dentífricos, las cremas para la higiene cutánea y algunos antisépticos bucales que,

63 (1929), De los sueros y vacunas en relación con el arancel y con el R. D. de 29 de febrero de 1928, Química e Industria, 6 (60), p. 14.

64 (1929), Las especialidades farmacéuticas y los tratados comerciales, Química e Industria, 6 (60), pp. 14-15. En opinión de la Unión Nacional de Laboratorios Químico Farmacéuticos, las legislaciones francesa e italiana permitían esta mutua reciprocidad, siempre y cuando las autoridades españolas lo diligenciaran, $c f$. (1929), Nuestras especialidades en Francia e Italia, Química e Industria, 6 (61), pp. 44-45; sobre este mismo asunto, véase también: (1929), Nuestras especialidades en Italia, Química e Industria, 6 (62), p. 72. Un par de años más tarde, Santiago Pagés Maruny abundaba en este asunto, $c f$. La Vanguardia, miércoles 22 de octubre de 1930 , p. 9.

65 (1929), Las especialidades farmacéuticas y los tratados comerciales, Química e Industria, 6 (60), pp. 14-15. 
pensaban, deberían poderse fabricar y comercializar bajo la misma contribución «que se asigna al ejercicio de la industria farmacéutica» ${ }^{66}$. Solicitaban una disposición del Gobierno que atendiera estos asuntos y aclarara la situación contributiva a la que se deberían enfrentar los laboratorios de especialidades farmacéuticas preparadores de este tipo de sustancias. La contestación ofrecida por la Administración fue clara; si el preparado en cuestión estaba registrado como especialidad farmacéutica no sería necesario otro pago que el de la tarifa correspondiente como laboratorio farmacéutico; si, por el contrario, no lo estaba entonces debería contribuir como producto de perfumería ${ }^{67}$.

Sin embargo, buena parte de los productos para la higiene bucal, aunque estuvieran elaborados por laboratorios que, de manera habitual, se dedicaban a la preparación de especialidades farmacéuticas, no estaban registrados como medicamentos y, por lo tanto, a efectos de la Ley del Timbre no gozaban de los privilegios que tenían los productos medicinales. Según el Real DecretoLey de 11 de mayo de $1926^{68}$, los alimentos y medicamentos llevarían un timbre de cinco céntimos cuando el precio del producto estuviera entre 1 y 2 pesetas, y de diez céntimos para aquellos que excedieran las 2 pesetas; el resto de artículos pagarían, como mínimo, a razón de 15 céntimos, para precios comprendidos entre 1 y 3 pesetas.

Este segundo supuesto contributivo fue el previsto por la Administración para los dentífricos, una decisión explicitada a través de una Real Orden Circular del Ministerio de Hacienda, en opinión de Jorge Foret Benaudín presidente de la Cámara Nacional de Industrias Químicas y vocal del Consejo de la Economía Nacional - una disposición no publicada ni en la Gaceta ni en el Boletín Oficial del Ministerio y contraria a la Ley del Timbre de 11 de mayo de 1926; así se lo hizo saber al Ministro de Hacienda, en una carta en la que se solicitaba la inclusión de los productos de higiene bucal, a efectos de la Ley del Timbre, dentro de las especialidades farmacéuticas ${ }^{69}$.

Éste de los dentífricos no fue el único asunto de índole contributiva que preocupó a los laboratorios farmacéuticos, también llamaron la atención sobre

66 (1928), Laboratorios Químico-farmacéuticos, Química e Industria, 5 (53), p. 155.

67 Cf. (1928), Contestación ofrecida por la Administración de Rentas Públicas de Barcelona, Química e Industria, 5 (57), p. 247.

68 Gaceta, 20 de mayo de 1926.

69 (1928), Carta de Jorge Foret Benaudín al Ministro de Hacienda. Barcelona, 14 de abril de 1928, Química e Industria, 5 (55), pp. 198-199. En esta misma carta se recordaba que los desinfectantes, a efectos contributivos, se habían agrupado recientemente con las especialidades farmacéuticas, $c f$. R. D.-Ley de 11 de mayo de 1926 (Gaceta, 12 de mayo de 1926). 
otros productos imprescindibles para la fabricación de determinadas especialidades 70 ; es el caso del vidrio para inyectables, el cual consideraban indispensable para el mantenimiento de muchas industrias españolas y para el que, en 1926, propugnaron volviera a ser considerado, a efectos tributarios, como materia prima, tal y como se había reconocido en un arancel anterior ${ }^{71}$.

\section{COROLARIO}

El asociacionismo farmacéutico industrial, al igual que ocurriera en otras actividades empresariales, experimentó un auge notable en España durante la Dictadura de Primo de Rivera. Los mecanismos proteccionistas para controlar la economía nacional, trazados por el gobierno del Directorio Militar, favorecieron las ansias monopolísticas de este grupo profesional, tanto en su vertiente de venta al por menor como en su faceta industrial.

La Unión Farmacéutica Nacional fue el organismo corporativo que, a partir de 1913, representó los intereses de un colectivo que, desde que se popularizara el medicamento industrial en nuestro país, comenzaba a dividirse en dos grandes grupos: aquéllos que fabricaban medicamentos y quienes los dispensaban. La inclusión de la farmacia industrial en la Cámara Nacional de Industrias Químicas terminó por desligar a los fabricantes de especialidades farmacéuticas del ejercicio tradicional de esta profesión y, por supuesto, del entramado corporativo generado por la Unión Farmacéutica Nacional, el «grupo de presión» que defendió, con notoriedad e ímpetu, los intereses de las oficinas de farmacia ante las autoridades gubernamentales y, también, ante sus colegas del área industrial, tanto durante la Dictadura como durante la II República.

La Cámara Nacional de Industrias Químicas se crea en Barcelona, hacia 1919, en una época de fortalecimiento de las asociaciones y conglomerados patronales, siguiendo la estela de la francesa Sociéte de Chimie Industrielle, y prolongó su existencia hasta que fue asimilada por la Organización Sindical

70 Incluso se llegó a proponer la implantación corporativa de una fábrica mecánica de vidrio, cf. (1928), Consejo Directivo. 5 de octubre de 1928, Química e Industria, 5 (58), pp. 269-270. Meses después volvería a ser tratado este tema en las páginas de Química e Industria, solicitando a los laboratorios que aún no hubiesen enviado la información solicitada lo hicieran «reservadamente», $c f$. (1929), Del proyecto para establecer una fábrica mecánica de vidrio, Química e Industria, 6 (61), p. 44.

71 Cf. (1926), Tubos calibrados de vidrio para inyectables, Química e Industria, 3 (27), p. 105. 
franquista, en 1939. La Cámara trató de defender, promocionar y representar a la industria química nacional ante posibles amenazas o situaciones desfavorables para sus intereses, valiéndose para ello de una estructura organizativa de tipo federal formada por «Uniones Nacionales» que, en la práctica, asumieron el control corporativo de su actividad respectiva.

Dentro de la Cámara Nacional de Industrias Químicas, los asuntos relacionados con los productos farmacéuticos fueron gestionados por la Unión Nacional de Laboratorios Químico-Farmacéuticos, presidida por el catalán Santiago Pagés Maruny. Esta asociación defendió los intereses de los laboratorios productores de especialidades farmacéuticas $\mathrm{y}$, por supuesto, del producto medicinal que comercializaban, utilizando para ello los recursos y mecanismos habitualmente empleados por los grupos empresariales de presión.

La Unión Nacional de Laboratorios Químico-Farmacéuticos actuó como patronal, durante la República, en Barcelona y trató de mediar ante el boicot del colectivo médico hacia los medicamentos procedentes de Cataluña. Realizó una labor destacada en la promoción y reivindicación de las especialidades farmacéuticas como soporte medicinal óptimo, y fue capaz de negociar con la UFN un acuerdo para regular el precio de las especialidades farmacéuticas, recuperando así compromiso, complicidad y solidaridad con sus compañeros de oficina de farmacia, lo que, sin duda, contribuyó a la expulsión de drogueros y otros comerciantes del negocio del medicamento, y al establecimiento de un monopolio que aún hoy perdura.

No fueron éstos los únicos asuntos de los que se ocupó esta organización, también trató de mediar con el fin de favorecer las exportaciones de medicamentos en condiciones favorables para sus asociados, principalmente con Portugal y países de América Latina; solicitó condiciones ventajosas para algunos productos en la frontera medicinal, como los de higiene bucal y cosmética, o imprescindibles para la fabricación de medicamentos, como el vidrio para inyectables; y trató de involucrarse, con éxito desigual, en la redacción de normas legales relacionadas con la publicidad, el control sanitario de especialidades farmacéuticas y productos biológicos, y la regulación de estupefacientes y medicamentos sometidos a vigilancia singular.

Recibido: 15 de junio de 2010.

Aceptado: 15 de noviembre de 2010. 